(c) 2008 Elsevier Inc. All rights reserved.

\title{
Environmental risk assessment: A critical approach of the European TGD in an in situ application
}

\author{
I. Guérit ${ }^{a}, G$. Bocquené ${ }^{a,{ }^{*}}, A$. James $^{a, b}, E$. Thybaud ${ }^{b}$ and C. Minier ${ }^{c}$ \\ a IFREMER, Département Biogéochimie et Ecotoxicologie, Cellule d'Analyse des Risques Chimiques, Rue de l'lle \\ d'Yeu, BP 21105, 44311 Nantes Cédex 03, France \\ ${ }^{b}$ INERIS, Parc Technologique Alata, BP 2, 60550 Verneuil-en-Halatte, France \\ c LEMA, UPRESSEA 3222, Université du Havre, Rue Lebon, 76058 Le Havre, France \\ *: Corresponding author : Bocquené G., email address : Gilles.Bocquene@ifremer.fr
}

\begin{abstract}
:
The aim of this study was to test field relevance of the prospective methodology for the assessment of environmental risk described in the EU technical guidance document (TGD) [European Commission 2003. Technical guidance document in support of Commission Directive 93/67/EEC on Risk assessment for new notified substances and Commission Regulation (EC) No 1488/94 on Risk assessment for existing substances and Commission Directive (EC) 98/8 on biocides, second ed. European Commission, Luxembourg, Part 1, 2 and 3, 760pp.]. To achieve this goal, an environmental risk assessment was performed according to the TGD for two major contaminants, atrazine and diuron, that are present in the Seine River estuary (France) and listed in the EU Water Framework Directive (Directive 2000/60/CE). Results showed that atrazine presented a source of risk in the upperand mid-estuary throughout the 1993 and 1996 spring seasons. Diuron introduced a risk into the same areas throughout spring periods of 1993-2005. Results are discussed and some suggestions for a more realistic in situ risk assessment are given. For the computation of a more relevant PNEC for pesticides, their specific mode of action should be taken into consideration as well as ecotoxicological data on species endemic to the considered area.
\end{abstract}

Keywords: Chemical risk assessment; Technical guidance document; The Seine River; Estuaries; Atrazine; Diuron 
Introduction

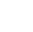

2

molecules into aquatic ecosystems, a certain number of measures and regulations have been set up by EU member states. In 1991, Directive 91/414/EEC dealing with pesticides authorization was approved. This directive considers that it is necessary to make sure that pesticides do not have unacceptable impacts on the environment. It focuses on phytopharmaceutical products and introduces for the first time the need for environmental risk assessment in the EU.

The Directive 2000/60/EC or "Water Framework Directive” (WFD) aims at providing a «good status » for surface waters (freshwaters, estuarine and marine waters) and underground waters by 2015. This good status is characterized by both good chemical and ecological status. The good chemical status of water bodies is defined in reference to the Environmental Quality Standards established fot 33 priority substances (Annex X of the directive) and 9 other substances or families of substances (Annex IX), i.e., a total of 41 substances (15 pesticides, including atrazine and diuron, 4 metals and 22 diverse organic substances).

A new European regulation, "REACH", has recently been approved to govern chemical substances (Regulation (EC) No 1907/2006) (EUROPA, 2007). The "REACH” acronym stands for "Registration, Evaluation, Authorization and restriction of Chemicals". According to this new regulatory framework, the onus of proof falls onto chemical manufacturers. Prior to commercialization, all new substances must undergo assessment to ascertain there are no possible environmental and human risks or that these risks are acceptable. REACH came into force on the $1^{\text {st }}$ of June 2007. European companies producing or importing more than 1 ton per year of chemicals will have to provide appropriate measures to manage risks to the environment and human health. However, REACH includes a specific authorization procedure for the use of "extremely hazardous substances". This procedure applies to substances that can lead to cancer, sterility, genetic mutations or congenital abnormality as well as persistent and bioaccumulative substances. Implementation of both WFD and REACH regulation relies on environmental risk assessment methodology described in the Technical Guidance Document.

Based on concepts associated with ecological risk assessment as proposed by the United States Environmental Protection Agency (US-EPA, 1998), the European methodology for chemical risk assessment is set out in the EU “Technical Guidance Document” (TGD) (European Commission, 2003). TGD is a guidance developed to prevent environment and human from risks of chemical substances. It is commonly used for 
assessment of chemical risks. Establishment of Environmental Quality Standards is also based on this methology. On the other hand, it is a somewhat uncommon practice to perform TGD application tests with a retrospective aiming at performing assessment of substances in the field (Villa et al., 2003a; Villa et al., 2003b).

Chemical contamination of aquatic environments due to pesticides has become a major environmental issue in recent years. The impact of pesticides upon the environment is difficult to establish specifically apart from the immediately visible impact of certain accidental spills. The difficulty to characterize those herbicides effects from the general impact of other contamination is due to exposure to complex combinations of various industrial, household and agricultural contaminants present in the same environment at the same time. While wastes are treated in order to reduce the number of domestic and industrial molecules dispersed into the environment, the widespread use of pesticides and their destructive properties make them considered as priority contaminants in terms of ecological impact. Due to their final vocations, pesticides do not only seriously jeopardize certain living processes but they can equally seriously threaten biodiversity.

There are three large pesticide families known to be major hazardous molecules to aquatic systems due to their specific mode of action : herbicides, insecticides and fungicides. Among them, herbicides cause environmental problems mainly due to the amounts involved and their ubiquitous nature in the aquatic environment. The two substances studied in this chemical risk assessment are atrazine and diuron, two herbicides listed on the priority list of substances (Annex X) of the European Directive 2000/60/EC or "Water Framework Directive" (WFD). The occurrence of atrazine and diuron in the environment derives from their use as herbicides or weed killers. In France, atrazine has been widely used for forty years since its introduction in 1960 until it was totally banned in 2003. Diuron is mainly used for non agricultural purposes and sometimes as an active substance in antifouling paints applied on boat hulls.

The aim of this work was to apply the European methodology described in the Technical Guidance Document to the Seine Estuary, in order to assess the environmental risk pertaining to two herbicides and to examine the possibility of improving this methodological tool for better in situ approaches.

\section{Materials and Methods}


Place of study

The Seine River is an area of considerable interest due to its substantial primary productivity, which is the first link of the sea trophic chain. It receives inputs from the side basin $\left(79,000 \mathrm{~km}^{2}\right)$ and is home to 17 million inhabitants (most of whom live in the vicinity of Paris). Moreover, it receives $40 \%$ of French industrial and farming activities (Lafite and Romaña, 2001). This results in a serious chemical contamination of the area, due for parts to phytosanitary substances (Tronczynski et al., 1999). Taking the basin as a whole, pesticide consumption is estimated to be between 20,000 and 30,000 tons p.a. (Comité de Bassin Seine Normandie, 2004).

This considerable and widespread use can lead to general pollution due to runoff and leaching (Lafite and Romaña, 2001; Miramand et al., 2001).

According to Fairbridge (1980) classification and its application on the river by Guézennec et al. (1999), three areas of the Seine estuary have been marked out as follows (Fig. 1):

- the upstream estuary or river estuary from the Poses dam to Vieux-Port (upper limit of seawater propagation);

- $\quad$ the mid estuary, from Vieux-Port to Honfleur ;

- $\quad$ the sea estuary, from Honfleur to the bay of the Seine River.

\section{Chemicals studied}

Atrazine is an herbicide widely used in agricultural practices until its ban in 2003 . The moderate solubility of atrazine in water $\left(33 \mathrm{mg} \cdot \mathrm{L}^{-1}\right.$ at $\left.22^{\circ} \mathrm{C}\right)$ and its quite low Henry's law constant $\left(1.5 \cdot 10^{-4} \mathrm{~Pa}^{-3} \mathrm{~m}^{-3} \cdot \mathrm{mol}^{-1}\right)$ and log $\mathrm{K}_{\mathrm{OW}}$ (2.5) makes it more likely to occur in the water column (FHI, 2005a). Degradation studies on atrazine give very controversial results depending on environmental conditions. Half-lives of 42 to 120 days have been calculated (Cunningham et al., 1984; Rice et al., 2004; Hackett et al., 2005). Given that atrazine has been shown to be more inhibitory to photosynthesis than its transformation products (Stratton, 1984; Eisler, 1989), it was decided not to take atrazine degradation into account in this risk assessment study in order to create a "worst case scenario". Diuron is an herbicide used in agricultural practices as well as an active substance in antifouling paints applied on boat hulls. Like atrazine, movements of diuron are favored in the dissolved state due to a moderate solubility in water $\left(35 \mathrm{~m} \cdot \mathrm{L}^{-1}\right.$ at $20^{\circ} \mathrm{C}$ and $42 \mathrm{mg} \cdot \mathrm{L}^{-1}$ at $\left.25^{\circ} \mathrm{C}\right)$, a low vapor pressure $\left(1.110^{-6} \mathrm{~Pa}\right.$ at $\left.25^{\circ} \mathrm{C}\right)$ and a $\log \mathrm{K}_{\mathrm{OW}}<3$ (2.55) (FHI, 2005b). Diuron is considered to be more persistent than atrazine. Haynes et al. (2000) gives a 120 
days aquatic half-life for diuron. Consequently, no degradation process was either taken into account in the modelling of this molecule.

Environmental risk assessment methodology (European Commission, 2003)

The TGD was developed as a guidance to prevent environment and human from risks of chemical substances. It is based on a 3 steps iterative process: problem formulation, analysis of exposure and effects and risk characterization (Fig. 2). The principle of risk assessment of chemical substances described in the TGD is based on the relationship that can be established between the level of a well-known contamination that can be reasonably predicted in the environment (Predicted Environmental Concentrations: PECs) and the threshold of unacceptable effects of this substance upon representative organisms of the relevant environment (Predicted No Effect Concentrations for the structure and the functioning of the ecosystem: PNECs). The atrazine and diuron PNECs taken into consideration by the EU are respectively $0.6 \mu \mathrm{g} . \mathrm{L}^{-1}$ (FHI, 2005a) and $0.2 \mu \mathrm{g} . \mathrm{L}^{-1}$ (FHI, 2005b). In deterministic risk assessments, risk characterization is the last step that consists in calculating the PEC/PNEC ratio. When the PEC/PNEC ratio equals one or more, it means that a potential risk to the environment is likely to occur.

\section{Modelling tools}

For the whole estuary, PECs were calculated with a hydrodynamic model using monitoring data. Such a hydrodynamic model is required to simulate behavior and fate of contaminants in order to calculate their theoretical concentrations in the different areas of the river and estuary. Given the fact that it was created and validated in the Seine estuary, it was decided that the SIAM 3D model developed by IFREMER would be used. The SIAM-3D is a tridimensional hydrodynamic model that calculates the transport of dissolved or particulate matter in a coastal environment. The model makes it possible to simulate dispersion of organic matter, nutriments, metal traces and soluble organic contaminants in real conditions of flow, tide and wind. In this model, the whole of the Seine bay is meshed (downstream area) from Cherbourg in the west, to Pays de Caux in the east and as far as central Manche in the north. Upstream the Seine River, it goes as far as the Poses dam which is the point of upstream tidal limit propagation, $150 \mathrm{~km}$ from the mouth (Cugier and Le Hir, 2000). 
The SIAM-3D model is used to calculate herbicide concentrations within the area of study.

In order to create a "worst case scenario", the annual maximum concentration of atrazine and diuron measured by the tracking system of the Service de Navigation de la Seine is used as input data for the level of the upstream limit of the model (Poses). The simulation is conducted with a constant input of herbicide associated with a variable water flow corresponding to the flows measured during the relevant period. The simulation is performed over a 56-day period, a duration time which corresponds to two tidal cycles and which is lower than the maximum water residence time of 60 days for conservative contaminants within the Seine estuary (Thouvenin $e t$ al., 1999).

The SIAM-3D model was validated by its creators (Cugier and Le Hir, 2002). In this study, environmental concentrations of atrazine calculated by the model have been compared with data measured by Tronczynski et al. (1999) during oceanographic campaigns in the Seine estuary. Values calculated for 1996 are consistent with values measured by Tronczynski et al. (1999) on the same sites and at the same time. These observations allowed the validation of the model for hydrophobic conservative contaminants.

\section{Monitoring of atrazine and diuron in the Seine River estuary}

Thanks to the Service de Navigation de la Seine, the Réseau National de Bassin has been monitoring both atrazine (from 1993 until now) and diuron (from 1997 until now), and continues to take samples of the Seine River estuary from Poses dam to Honfleur every 15 days (Fig. 3 and Fig. 4) up to now. Three sites (Poses, La Bouille and Caudebec en Caux) are monitored.

Atrazine and diuron are analyzed as follows: sampling is realized by collecting five liters of water and filtering the water to separate particulate phase from dissolved phase. Samples are then immediatly vacuum-filtered using fiberglass filters and solid phase extraction (SPE). OASIS HLB (Waters, St Quentin en Yveline, France), a copolymer of pyrolidone and divinylbenzene, is used as a sorbent as it allows efficient recovery and extraction of atrazine and diuron. The dissolved phase is used for atrazine and diuron extraction. After evaporation of the extract solution to near dryness using a gentle stream of nitrogen and dissolution of the residue in a solvent adapted to the chromatographic technique, analysis are performed with gas-chromatography (thermoionic nitrogen/phosphorus detector or ion trap mass spectrometer : column : $60 \mathrm{~m}$; DB5;0,25 mm ; 0,25 $\mu \mathrm{m}$ ). Detection limit is 2 ng. $\mathrm{L}^{-1}$ for both atrazine and diuron. 
It must be noticed that sampling takes place every 15 days and that it is very likely that measured values do not correspond to the highest points of the real contaminant input. Over the 1993-2005 period, the highest atrazine concentrations found in water were observed in Poses (Fig. 3), upstream of Rouen (0.61 and 0.65 $\mu$ g.L $\mathrm{L}^{-1}$ in 1993 and 1996 respectively). Over the 1997-2005 period, the highest diuron concentrations found in the Seine River were observed in La Bouille (Fig. 4), downstream of Rouen (1.28, 0.91 and $0.95 \mu$ g.L $^{-1}$ in 1997, 1999 and 2000 respectively), except for 2001 and 2004 when the maximum concentrations were observed in Poses in the upper part of the estuary ( 1 and $0.54 \mu \mathrm{g} . \mathrm{L}^{-1}$ in 2001 and 2004 respectively).

Some NOECs for atrazine and diuron for a single aquatic food chain (three trophic levels: plancton, invertebrate, vertebrate) are given in Table 1 (FHI, 2005a; FHI, 2005b). These data stress the fact that atrazine and diuron have a major impact on phytoplanctonic communities. 90

\section{The validation of the dispersion model}

The SIAM 3D model was used to simulate dispersion of atrazine from the upstream estuary towards the sea estuary. A covariance statistical analysis performed on the measurements of atrazine made on the three sites (Poses, La Bouille and Caudebec en Caux) from 1993 to 2005 showed that there are no significant intraestuarine inputs in this part of the estuary. The hydrodynamic model was tested to confirm the choice of the simulation parameters. The results obtained by the model in the sea estuary were compared to the in situ measurement during an oceanographic campaign in the same area in June 1996 (Tronczynski, personal communication). A constant input concentration of $0.32 \mu \mathrm{g} . \mathrm{L}^{-1}$ of atrazine (concentration measured at Poses site by Troncsynski in June 1996) was set up with a variable flow measured in the Seine River at the same period of time. Within the sea estuary, concentrations measured in situ and concentrations calculated by the model are either identical or very similar (Fig. 5). Values calculated for 1996 are consistent with values measured by Tronczynski et al. (1999) on the same sites and at the same time. These observations confirms the validation of the model for hydrophobic conservative contaminants. 


\section{Results}

Assessment of the environmental risk related to atrazine

210

Given the biogeochemical behavior of atrazine, the dispersion in the Seine estuary was achieved in the water column. Period of study was 1993 to 2005 due to availability of monitoring data. In June 1993 and October 1996, atrazine concentrations measured and/or calculated in the upstream and mid estuary were above the PNEC value of $0.6 \mu \mathrm{g} . \mathrm{L}^{-1}$. Therefore, for this period, the PEC/PNEC ratio exceeded 1 and an environmental risk linked to the presence of atrazine was shown in upstream and in mid estuary areas during the spring period (Fig. 6). On the other hand, except for only one part of the sea estuary in 1993, there was no risk in this area (PECs $<$ PNECs). Albeit high concentrations in upstream and mid estuary areas, PECs remained below the PNEC (concentrations ranging between 0.45 and $0.6 \mu \mathrm{g} . \mathrm{L}^{-1}$ ) after the implementation of the first measures to restrict the use of atrazine in 1997. Therefore, the risk receeded from 1997 until 2005. From 2000 onwards, atrazine concentrations dwindled and dipped below $0.15 \mu \mathrm{g} . \mathrm{L}^{-1}$ for the whole of the area as from 2002. Therefore, following the TGD methodology and considering solely the impact of atrazine, the upstream and mid estuaries of the Seine River were subjected to a potential risk during spring periods of 1993 and 1996.

Assessment of the environmental risk related to diuron

The simulation of diuron dispersion covered 1997 to 2005 but the years with the highest concentrations are merely described (Fig. 7).

Throughout this period, concentrations of diuron exceeded the PNEC determined for this substance $\left(0.2 \mu \mathrm{g} . \mathrm{L}^{-1}\right)$ on both the upstream and mid estuary areas. In this part of the estuary, the PEC/PNEC ratio exceeded 1, thus implying a potential risk for the ecosystem. Only one part of the sea estuary was submitted to the same level of risk. The risk assessment applied to the Seine River revealed a diuron-induced risk within the mid and upstream estuaries during the spring, summer and autumn from 1997 to 2005. The risk lasted 4 to 7 months depending on the year. 
An environmental risk assessment was carried out on the two herbicides typical of contamination in the Seine River estuary (France). The analysis was performed in accordance with the methodology described in the Technical Guidance Document, the European reference guide of environmental risk assessment. The analysis was both conceived and built around a prospective approach aiming at providing background data pertaining to environmental risk prior to the marketing authorization dossier of new chemical substances and in compliance with EU rules. In its current form, the TGD does not have the immediate purpose of assessing real in situ risk within a multi -contaminated natural environment. This work aims to apply TGD methodology to the Seine estuary and to discuss the relevance of this methodology using a retrospective in situ approach. during the spring, summer and autumn periods of years 1993 to 2005.

Whenever the risk assessment shows a potential risk for the environment (PEC/PNEC > 1), the TGD procedure (Fig. 2) recommends that a certain number of iterative steps should be taken prior to implementation of any measures, i.e., that more data should be looked into when made available by industrials. As a result, the PEC/PNEC ratio must be adjusted. In an in situ study, PECs mainly come from concentrations measured directly in the environment or calculated by means of a dispersion model validated with measured data. Therefore, there are fewer opportunities for adjusting the PECs. In addition, in our study, calculations of atrazine dispersion by the model are validated by measurements made in the field, and it is thus founded to generally apply this validation to all hydrosoluble contaminants displaying, like atrazine, conservative behavior throughout the duration of the simulation. In these conditions, PNEC is the value that can most likely be adjusted. PNECs are defined on the basis of ecotoxicological tests related to survival, growth and reproduction of species belonging to at least 3 different trophic levels (algae, crustaceans and fish) simulating a basic trophic chain. PNECs are calculated from No Observed Effect Concentrations (NOECs) or other effects concentration (EC50 or LC50). Using this approach, the diversity and the structure of the ecosystem are expected to be safeguarded by the protection of the most sensitive species and therefore, it is assumed that the very best functioning of the ecosystem itself is guaranteed. 
According to TGD methodology, PNECs can be derived using two different methods, depending on quantity and reliability of data for a given molecule. These two methods are described as follows :

- by means of the application of an extrapolation factor to the available ecotoxicological dataset. The extrapolation factor is chosen applying "expert judgement". This judgement is a function of quality and quantity of data. These assessment factors recommended in the TGD are considered as conservative and protective factors and range from 10 to 1,000 for freshwaters and from 10 to 10,000 for estuarine and marine waters.

- by means of the statistical extrapolation method, based on Species Sensitivity Distribution (SSD) approach, when the ecotoxicological dataset of the substance is sufficient, i.e., at least 10 NOECs (preferably more than 15) for 8 different taxonomic groups. A "Hazardous Concentration 5" (HC5), which is the $5^{\text {th }}$ percentile of the SSD is then divided by an extrapolation factor to derive the PNEC. This extrapolation factor ranges from 1 to 5 and it is based on expert judgement.

Within the context of the WFD, PNECs have been validated for all the priority substances. Atrazine and diuron are well-known contaminants for which dataset are quite substantial. PNEC for atrazine was calculated using statistical extrapolation based on mesocosms data. Although many data are available for diuron, the number of taxonomic groups represented is not high enough to apply the statistical extrapolation method. Therefore, PNEC for diuron was calculated with the extrapolation factors method.

Some specific issues of any given in situ study are not taken into account in the PNEC derivation methodology of the TGD. The specificity of the mode of action of the substance, i.e., specific hazards underlying the effects of the molecule, is an important factor in understanding the ecological risk. Substantial quantities of atrazine flowed through the Seine estuary : in total 2850 k/p.a. in 1994 and 2750 k/p.a. in 1995 (Tronczynski et al., 1999). If atrazine affects survival, growth and development of aquatic insects (Dewey, 1986) as well as swimming behavior of fish (Steinberg et al., 1995) and given the way this herbicide works (photosynthesis inhibitors), the available toxicological data demonstrates a sizeable impact on the algal community. Jones and Winchell (1984) have shown that the inhibition of aquatic macrophyte photosynthesis increases with increasing atrazine concentrations. The NOEC for atrazine measured on the chlorophyce Scenedesmus subspicatus is 2100 times lower than the NOEC measured on the copepod Eurytemora affinis and 150 times lower than the NOEC in the fish Brachydanio rerio. This is also true for diuron : the crustacean Daphnia magna is 120 times less sensitive to diuron than the microalgae Scenedesmus subspicatus and this microalgae is 70 times less sensitive to diuron than the fish Pimephales promelas. As primary producers are at the base of trophic networks, it is reasonable to 
postulate that the inhibition of plant growth may have an impact on herbivores. If resources diminish, this could mean less availability of specific foods. Legrand et al. (2006) have shown that a low concentration of both herbicides atrazine and diuron $\left(0.1 \mu \mathrm{g} . \mathrm{L}^{-1}\right.$ of each) triggers a synergic effect of microphytobenthos photosynthesis inhibition as compared to the individual effect of each molecule alone. Atrazine and diuron act on the processes of photosynthesis in the same way (Haynes et al., 2000) and are used during the same periods (spring and summer). In addition, certain previously used formulations contained both molecules. They are therefore likely to produce additive or synergic effects. PNECs for herbicides should therefore be calculated from NOEC from toxicity tests on vegetal species mainly.

Another issue is the fact that PNECs generally come from ecotoxicity tests carried out on certain laboratory species. TGD methodology does not recommend a calculation of the PNECs using toxicity data on local species. Working on data issued from test on local species would give more relevance to the PNEC in the context of an in situ study. This could result in the development of "local PNECs", based on toxicity data obtained from local endemic organisms of the area of study with a strong ecological relevance in the local ecosystem, i.e., species considered as "key species". In the case of the Seine estuary, this "key species" could be Eurytemora affinis, an oligohalin copepod dominant in this estuary. E. affinis dominates the estuarine mesozooplanctonic community throughout the year thanks to conditions in the Seine River estuary that considerably favor its development. As a result, certain maximum densities exceed 190,000 individuals. $\mathrm{m}^{-3}$, i.e., an abundance an order of magnitude greater than in other European estuaries. It is preyed upon by many planctivorous and suprabenthic species as well as by fish that live in this upstream part of the Seine estuary (Mouny and Dauvin, 2002).

As part of the prospective TGD approach, PNEC calculation is based on ecotoxicological data divided by extrapolation factors ranging from 10 to 10,000 as a function of availability and reliability of ecotoxity data. A low extrapolation factor can only be used when one has a large and validated data set (European Commission, 2003). It must be kept in mind that in the case of atrazine and diuron herbicides, there is much data and this enables the allocation of a minimum safety factor given that one has NOECs at one's disposal for all three trophic levels. Thus, in all probability, the analysis is deemed relevant. When the toxicity of certain contaminants is poorly documented, the application of these extrapolation factors may lead to an assessment of a PNEC less realistic. The acquisition and use of toxicological data derived from organisms specific to the area of study would allow one to narrow factors and thus to obtain a better insight into the sensitivity of the environment. Finally, in the particular case of an estuary, the most realistic risk assessment could consist in determining a 
"local PNEC" for each of the three ecosystems: the upstream, the mid estuary and the sea estuary, which are the habitats of different living species.

Another question to be addressed when studying risk assessment is the validation and demonstration of an environmental risk in terms of a real damage to the ecosystem. In order to appraise the relevance of in situ risk analysis, the demonstration of a risk must be set against ecological data, thus confirming or dismissing the risk. In this study, one could ask whether an impact on the biological communities of phytoplankton has been observed further to the chemical risk caused by atrazine and diuron in the Seine estuary. Alternatively, is the impact of herbicides on primary production quantifiable when using data from the existing monitoring network ? A statistical study of existing dataset against monitoring of phytoplanktonic populations at a local level (the structure of the populations, chlorophyll concentrations) could provide essential information to address these important issues.

When applying TGD methodology with in situ data, accuracy of PNEC derivation is the decisive criterion. Indeed, one could suggest that for molecules that have a specific mode of action, e.g. herbicides and insecticides, ecotoxicological data on target species should be prioritized to improve the PNEC relevance. Moreover, derivation of PNEC should be based on ecotoxicological data issued from tests on species that are endemic to the place of study.

Acknowledgements.

Financial support from the Seine Aval Programme is gratefully acknowledged. C. Minier was supported in this study by the European Intereg III programme (Contract No. 156, RAED) 


\section{References}

Comité de Bassin Seine Normandie (2004). "Etat des lieux Bassin Seine et cours d'eau côtiers normands." Agence de l'eau Seine-Normandie et Ministère de l'Ecologie et du Développement Durable, Direction Régionale de l'Environnement - DIREN - Ile-de France - Bassin Seine-Normandie, 172 p.

Cugier, P. and Le Hir, P. (2000). "Three dimensional modelling of suspended matters in the eastern "baie de Seine" (English Channel, France)." Comptes Rendus de l'Académie des Sciences - Series IIA - Earth and Planetary Science 331(4): 287-294.

Cugier, P. and Le Hir, P. (2002). "Development of a 3D Hydrodynamic Model for Coastal Ecosystem Modelling. Application to the Plume of the Seine River (France)." Estuar. Coast. Shelf Sci. 55(5): 673-695.

Cunningham, J.J., Kemp, W.M., Lewis, M.R. and Stevenson, J.C. (1984). "Temporal responses of the macrophyte, Potamogeton perfoliatus L., and its associated autotrophic community to atrazine exposure in estuarine microcosms." Estuaries 7(4 - PartB): 519-530.

Dewey, S.L. (1986). "Effects of the Herbicide Atrazine on Aquatic Insect Community Structure and Emergence." Ecology 67(1): 148-162.

Eisler, R. (1989). "Atrazine hazards to fish, wildlife and invertebrates: A synoptic review." U.S. Fish Wildl. Serv. Biol. Rep. 85: 1-18.

EUROPA

(2007).

European

Commission

website, http://ec.europa.eu/environment/chemicals/reach/reach_intro.htm.

European Commission (2003). "Technical Guidance Document in support of Commission Directive 93/67/EEC on risk assessment for new notified substances and Commission Regulation (EC) No 1488/94 on risk assessment for existing substances and Commission Directive (EC) 98/8 on biocides. 2nd Edition." European Commission, Luxembourg. p.

Fairbridge, R., W. (1980). The Estuary : its definition and geodynamic cycle. Chemistry and Biogeochemistry of estuaries. E. Olausson, Cato, I. (Ed). Chichester, John Wiley and Sons. pp. 1-35.

FHI (2005a). "Common Implementation Strategy for the Water Framework Directive. Environmental Quality Standards Substance Data Sheet. Atrazine." $\quad$ Brussels. $21 \quad$ p. http://circa.europa.eu/Public/irc/env/wfd/library?l=/framework_directive/ipriority_substances/supporting_background/substance_sheets\&vm=detailed\&sb=Title. FHI (2005b). "Common Implementation Strategy for the Water Framework Directive. Environmental Quality Standards $\quad$ Substance $\quad$ Data Sheet. Diuron." $\quad$ Fraunhöfer $\quad$ Institute, $\quad$ Brussels. $17 \quad$ p. 
http://circa.europa.eu/Public/irc/env/wfd/library?l=/framework_directive/ipriority_substances/supporting_background/substance_sheets\&vm=detailed\&sb=Title.

Guézennec, L., Romaña, L.-A., Goujon, R. and Meyer, R. (1999). "Un estuaire et ses problèmes." Ifremer, Plouzané. 29 p.

Hackett, A.G., Gustafsona, D.I., Morana, S.J., Hendleyb, P.I., van Wesenbeeckc, I., Simmonsc, N.D., Kleind, A.J., Kronenberga, J.M., Fuhrmana, J.D., Honeggera, J.L., Hanzase, J., Healye, D. and Stone, C.T. (2005). "The Acetochlor Registration Partnership Surface Water Monitoring Program for Four Corn Herbicides." Journal of Environmental Quality 34: 877-889.

Haynes, D., Ralph, P., Prange, J. and Dennison, B. (2000). "The Impact of the Herbicide Diuron on Photosynthesis in Three Species of Tropical Seagrass." Marine Pollution Bulletin 41(7-12): 288-293.

Jones, T. and Winchell, L. (1984). "Uptake and photosynthetic inhibition by atrazine and its degradation products of four submerged vascular plants." J. Environ. Qual. 13: 242-247.

Lafite, R. and Romaña, L.-A. (2001). "A Man-Altered Macrotidal Estuary: The Seine Estuary (France): Introduction to the Special Issue." Estuaries 24(6B): 939.

Legrand, H., Herlory, O., Guarini, J.-M., Blanchard, G.F. and Richard, P. (2006). "Inhibition of microphytobenthic photosynthesis by the herbicides atrazine and diuron." Cah. Biol. Mar. 47: 39-45.

Miramand, P., Guyot, T., Rybarczyk, H., Elkaim, B., Mouny, P., Dauvin, J.-C. and Bessineton, C. (2001). "Contamination of the biological compartiment in the Seine Estuary by $\mathrm{Cd}, \mathrm{Cu}, \mathrm{Pb}$ and Zn." Estuaries 24(6B): 1056-1065.

Mouny, P. and Dauvin, J.-C. (2002). "Environmental control of mesozooplankton community structure in the Seine estuary (English Channel)." Oceanol. Acta 25(1): 13-22.

Rice, P., Anderson, T.A. and Coats, J.R. (2004). "Effect of sediment on the fate of metolachlor and atrazine in surface water." Environmental Toxicology and Chemistry 23(5): 1145-1155.

Steinberg, C.E.W., Lorenz, R. and Spieser, O.H. (1995). "Effects of atrazine on swimming behavior of zebrafish, Brachydanio rerio." Water Res. 29(3): 981-985.

Stratton, G.W. (1984). "Effects of the herbicide atrazine and its degradation products, alone and in combination, on phototrophic microorganisms." Archives of Environmental Contamination \& Toxicology 13: 35-42.

Thouvenin, B., Billen, G., Even, S., Fischer, J.-C., Gonzalez, J.-L., Le Hir, P., Loizeau, V., Mouchel, J.-M., Olivier, C. and Silva Jacinto, R. (1999). Les modèles : outils de connaissance et de gestion. Programme scientifique Seine Aval. Plouzané, Ifremer. 16. pp. 32. 
Tronczynski, J., Munschy, C. and Moisan, K. (1999). "Organic contaminants that leave traces : sources, transport

410 and fate." Ifremer, Plouzané. 40 p.

411 US-EPA (1998). "Guidelines for ecological risk assessment." U.S. Environmental Protection Agency, 412 Washington, DC. 124 p.

413 Villa, S., Finizio, A. and Vighi, M. (2003a). "Pesticide risk assessment in a lagoon ecosystem. Part I: Exposure 414 assessment." Environ. Toxicol. Chem. 22(4): 928-935.

415 Villa, S., Vighi, M., Casini, S. and Focardi, S. (2003b). "Pesticide risk assessment in a lagoon ecosystem. Part II 416 : Effect assessment and risk characterization." Environ. Toxicol. Chem. 22(4): 936-942. 


\title{
An environmental chemical assessment of two herbicides, atrazine and diuron, in the R iver Seine estuary \\ (France)
}

\section{On site application of the E uropean Technical G uidance Document (TGD)}

\author{
Guérit I., B ocquené G., J ames A ., Thybaud E., M inier C.
}

\section{$\underline{\text { Response to general comments from reviewer } 1 \text { and } 2}$}

We agree that objectives of the work were not clear enough and that there were some misunderstandings, mainly in the abstract and the introduction, the paper has been rew ritten to be clearer in its main objective. N evertheless, the study doesn't aim at developing a new risk assessment methodology. This study aims at discussing a methodology recommended by the European Commission that is a technical support in the process of authorization of marketing for chemical substances. 0 ther european directives recommend the application of this methodology.The risk assessment methodology described in the Technical Guidance Document (TGD) was developed as a theoretical prospective approach aiming at protecting the environment.

Authors of this study have applied this methodology in situ in order to weight its prons and cons in realistic environmental conditions.

The article was corrected according to reviewers' comments. Goals have been more clearly explained and discussion has been consolidated.

\section{Point after point responses to the reviewer}

Responses to review er 1

Abstract

- P2, L25-26. The sentence has been entirely rewritten.

Introduction

- $\quad P 4, L 42-45$. The sentence has been rewritten (it means it is difficult to specifically identify effets due to herbicides from global effects due to the whole contaminants. Moreover, the pesticides are directly dispersed in the environment while domestic and industrial wastes are partially treated through sewage.

- P4, L47-49. Sentence has been corrected in this way.The authors agree with the fact that insecticides and fungicides also impact the aquatic life.

- P5, L73-76. References for the REACH regulation have been provided. Objectives and supporting methodology for environmental risk assessment of the REACH regulation have been specified.

- P5, L85-87. We agree that the concept of PEC/PNEC approach has already been used many times in in situ risk assessment, but the TGD is not only application of the PEC/PNEC concept, it also described in details how PNEC must be theoritecally calculated from available toxicity data, and for some parts this work is about the relevance of the TGD in calculating the PNEC in a complex estuarine situation.

- P5, L91. The modeling is only used for calculation of real environmental PEC, on the basis of real data measured in situ in only few stations.

Materials and methods

- P7, L125: The PNEC calculation has been explained in more detail in the text. The Hazardous Concentration (HC) is quite different from the PNEC value. TGD recommends to base PNEC values upon HC when enough data are available to apply statistical extrapolation method. The TGD methodology requires to calculate the $\mathrm{PEC} / \mathrm{PNEC}$ ratio for risk characterization.

- P7, L129-145: The validation of the model was already described in the Results section now it has been transferred in the $M$ and $M$ section. 
- P7-8, L151-175: A uthors agree that this description should be transferred to M aterials and M ethods section. This transfer has been done.

- P7, L152: M onitoring: when ? This information is al ready given in the text.

- P8, L174: M aximum concentrations have been reported in the fig.2 (atrazine) and fig.3 (diuron).They also have been added to the text.

- P8, L177-180: Reviewer is right, the legend for the table 1 should be « M ain NOEC for atrazine and diuron in a single aquatic food chain ». The way PNEC are calculated within the TGD methodology is specified in more details.

- P8/9, L182-195 : In this exercice, the risk assessment is performed in the worst case conditions. Therefore, input data are maximum concentrations of atrazine and diuron that were measured in the upstream estuary. It has been demonstrated that residence time of a conservative contaminant in the estuary ranges from 30 to 60 days. M oreover, half lives of atrazine and diuron are respectively 42-120 days and 120 days (references added in the article).

\section{Responses to review er 2:}

Abstract

A bstract has been rewritten in order to give the information requested.

Introduction

- Setting up of sentences and paragraph has been reviewed.

- L47: The authors agree that insecticides do have environmental impact on ecosystem, particularly on marine species where crustacean species (mainly zooplanctonic copepods) have been showed to be very sensitive to A ChE inhibitors (organophosphorous and carbamate compounds). however, the study is about 2 herbicides widely used and that are efficient inhibitors of photosynthesis implied in disturbance of marine primary production and in disturbance of algal communities (Solomon et al., 1996. Schmitt-Jansen, Altenburger, 2004).

- L50: A uthors agree that more details should be given about TGD methodology. A scheme has been added to express more clearly the procedure.

Materials and Methods

- L105: A uthors agree with this comment that has been taken into account.

- L127-145-Modeling tools: The SIAM 3D model is not used according to the TGD. It is a local 3D morphohydrodynamic and ecological model of the Seine Bay created for studies of the Seine estuary and validated with measured concentrations in the Seine estuary. The SiA M -3D code simulates the transports of water, sand and mud. Its Seine-specificity is the reason why it was chosen for this study (information added in the article).

- references have been added about degradation processes of atrazine and diuron and how they were taken into account in the model.

Results

- U se of the word fortnight : remark has been taken into account

- U se of the « bullet »: this section (L 149-175) has been transferred in the M aterials and M ethods section and bullets have been suppressed.

- L193 : the SIAM 3D model has been validated many times for waters and suspended materials transports. Here again we give evidence of very similar values obtained with both analytical data and calculated data but number of data was not sufficient for an efficient statistical approach.

- Fig 4-6 : remark has been taken into account

\section{Discussion}

- First paragraph : It is a recall of the main findings that is the basis for the discussion to follow.

- L238 : authors agree that this sentence was not clear enough. The sentence has been consolidated and a Figure has been added (cited in $M$ aterials and $M$ ethods).

- $\quad$ L 262 : remark has been taken into account

Potential effects of degradation products: As specified now in the MM section, degradation products were not considered in the modelling. 
Figure 1. Zonation of the estuary according to Fairbridge classification (1980).

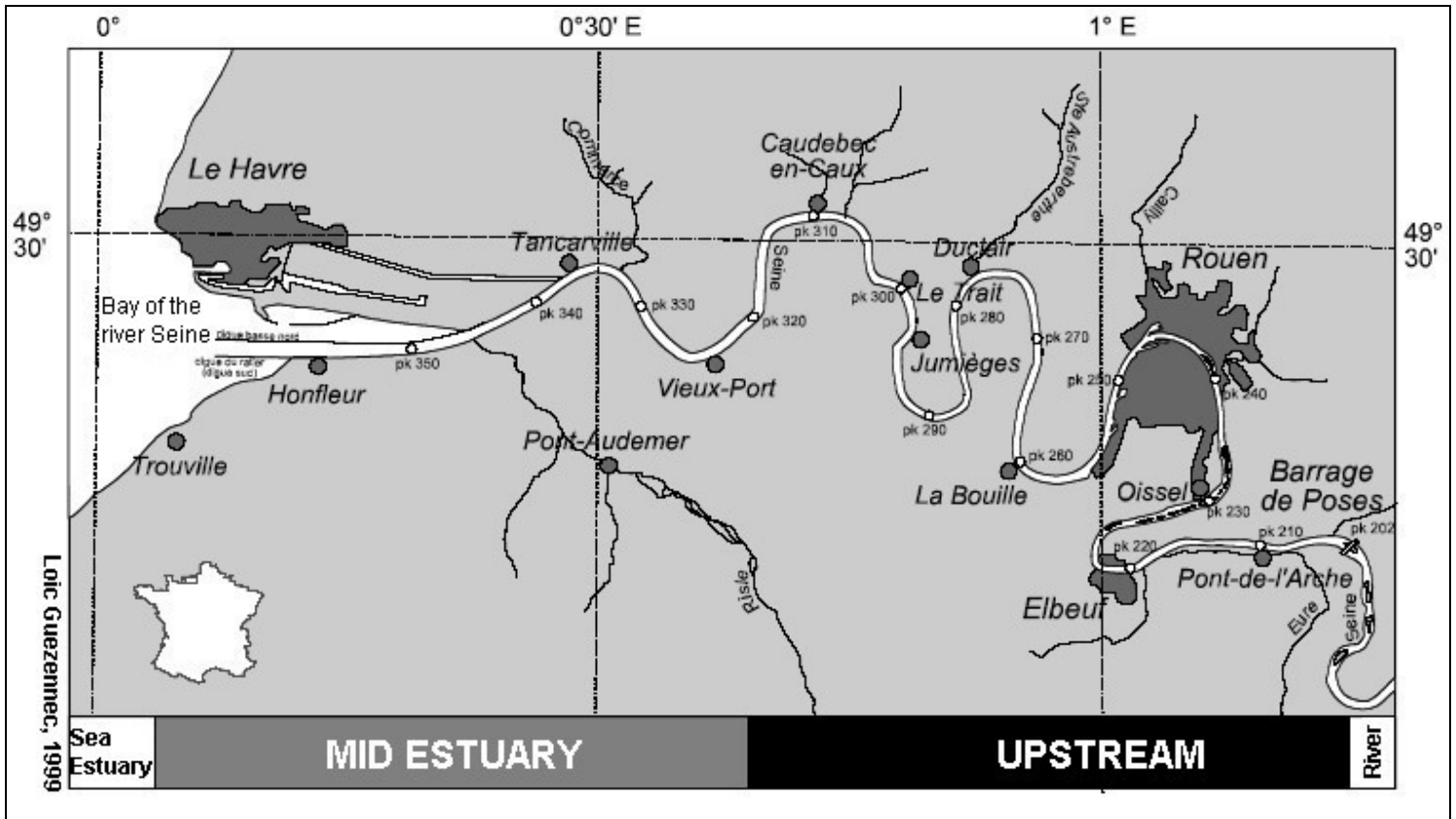


Figure 2. General procedure for risk assessment

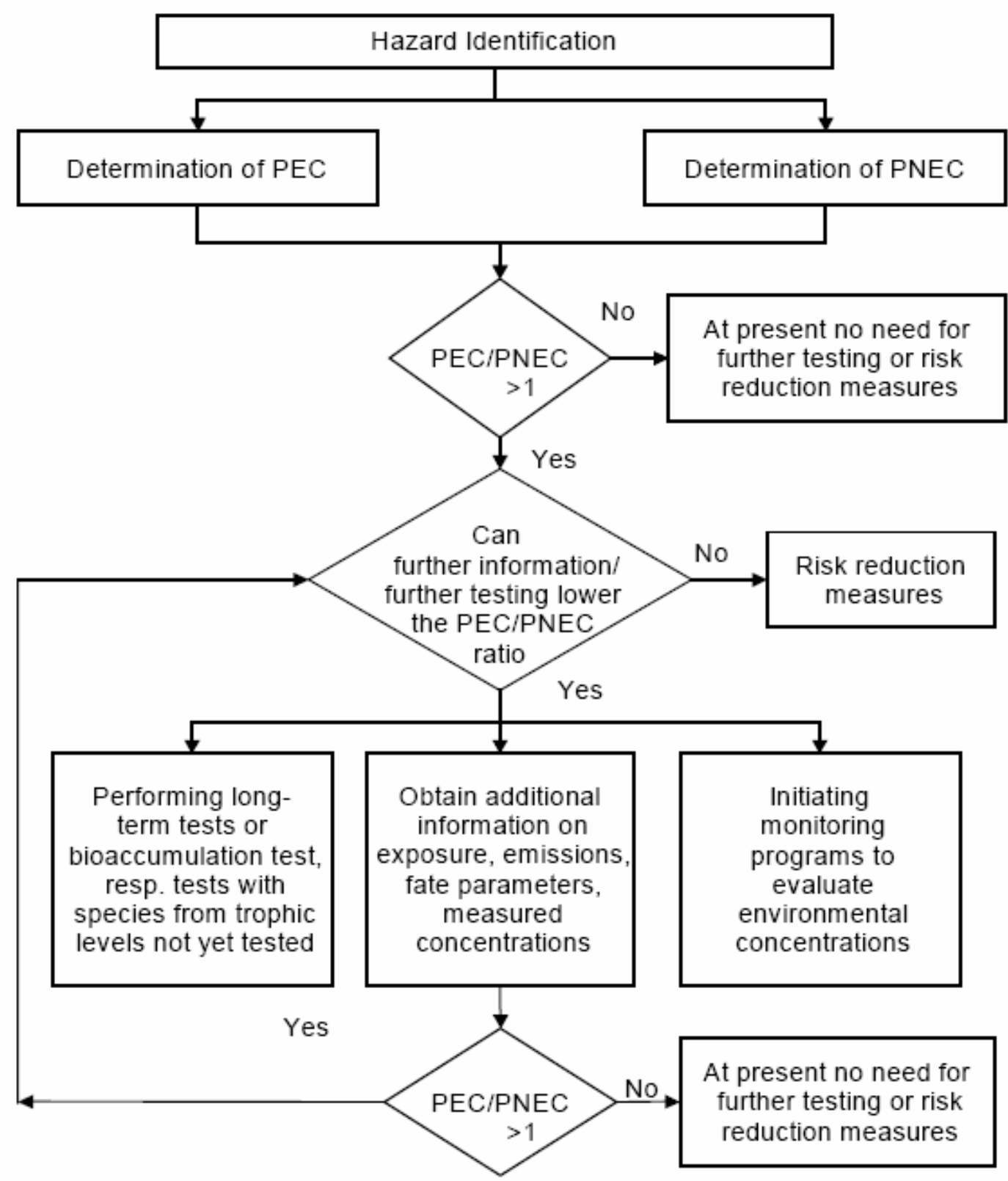


Figure 3. Variations in atrazine concentrations measured in raw waters at Poses from 1993 to 2005 (source: Services de Navigation de la Seine, Rouen)

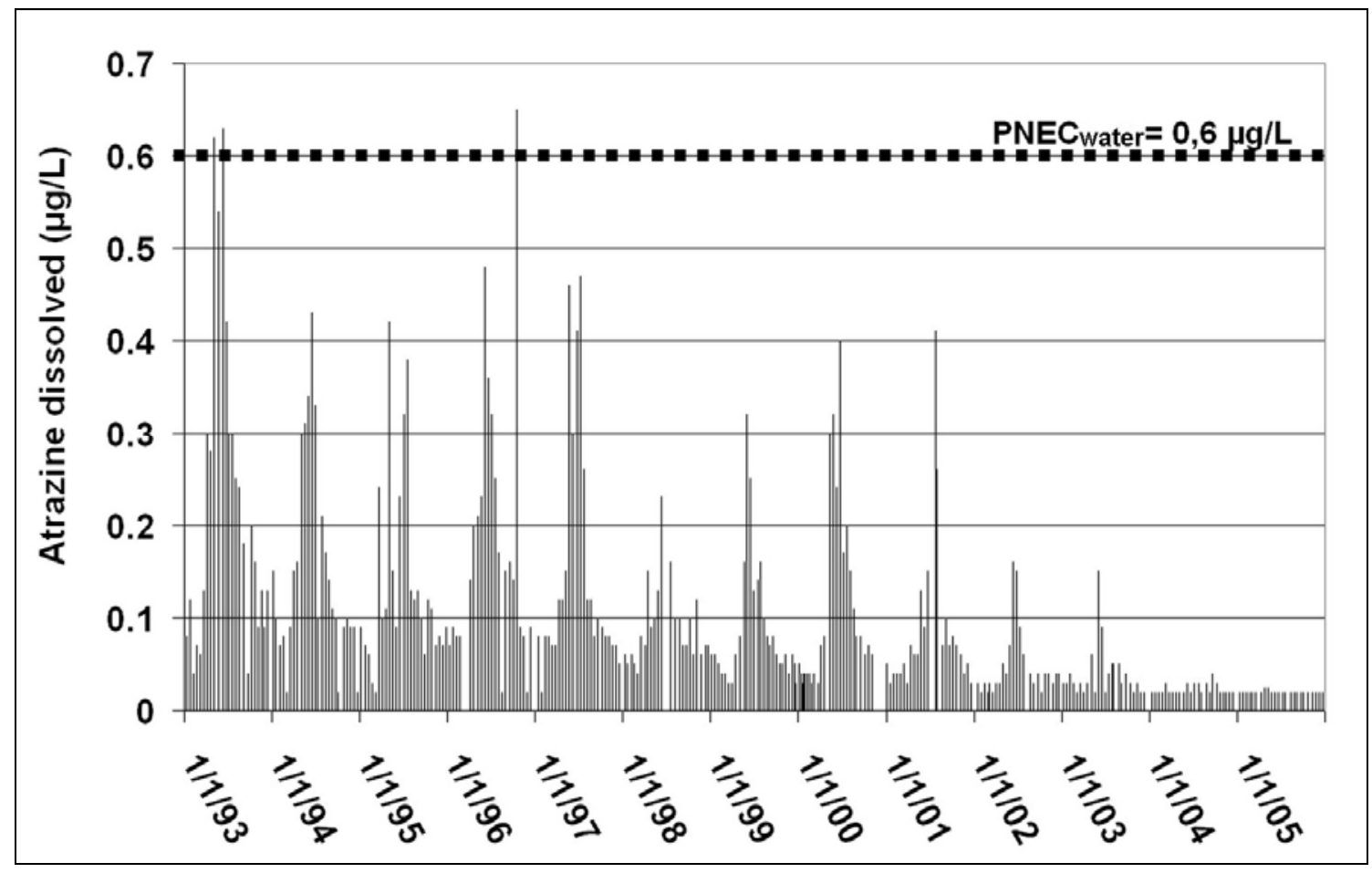


Figure

Figure 4. Variations in diuron concentrations measured in raw waters at La Bouille from 1997 to 2005 (source: Services de Navigation de la Seine, Rouen).

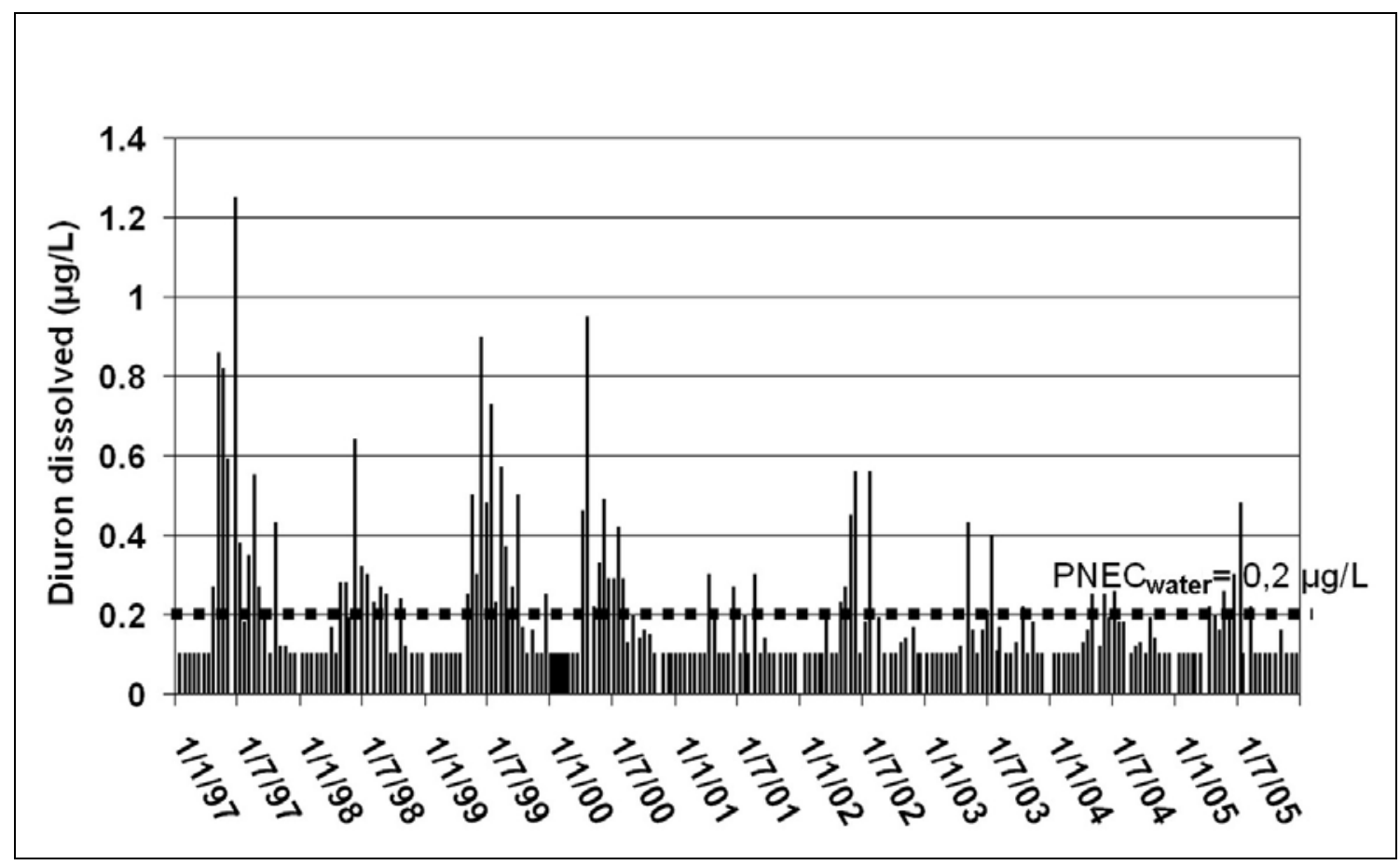

1 
Figure 5. Comparison of data measured in June 1996 (pointed out directly on the scheme) with the data calculated by the SIAM-3D model at the same period (indicated by the legend below the scheme).

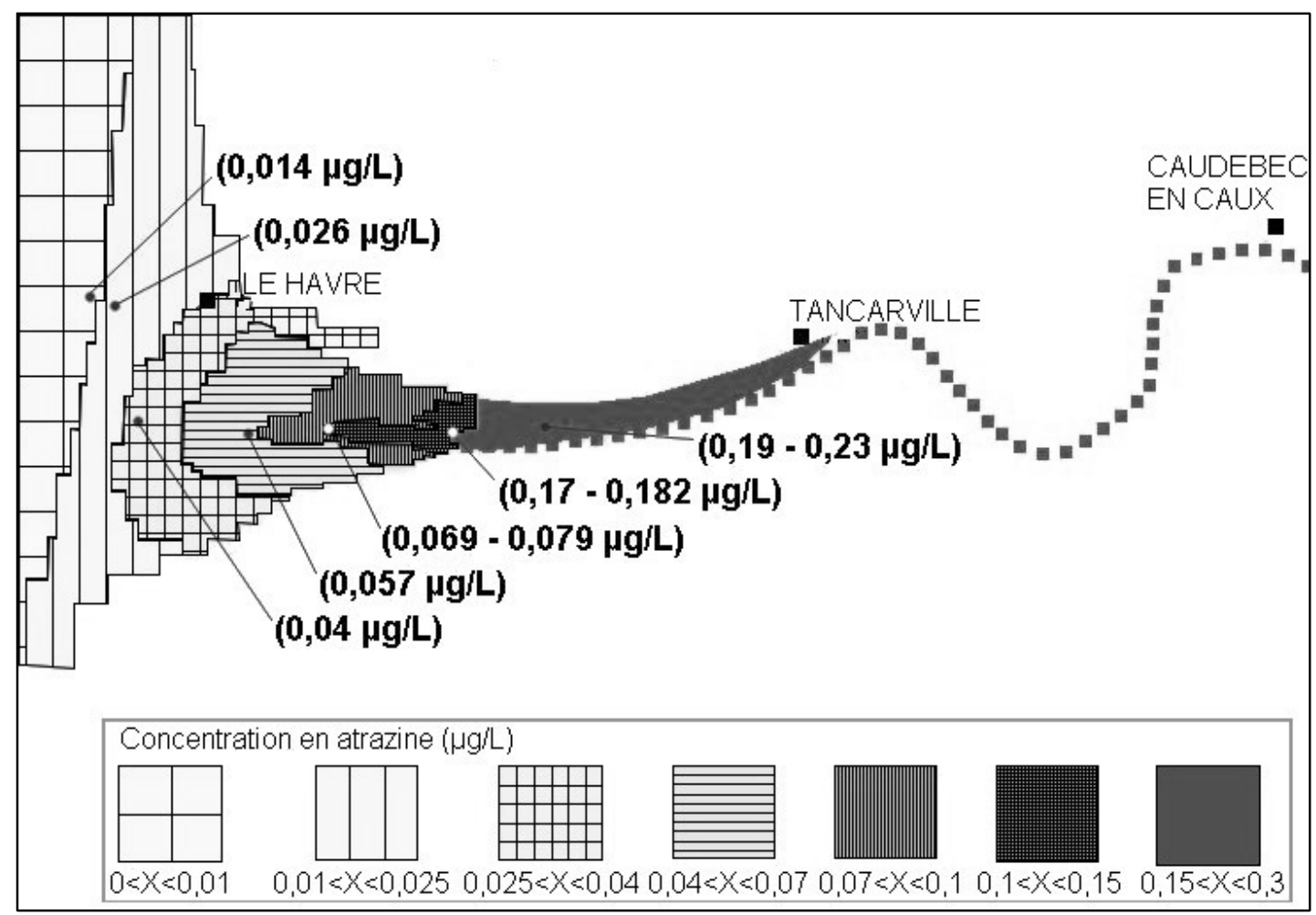


Figure 6. Results of the atrazine risk assessment in 1993, 1996, 1997 and from 2002 to 2005 . A PEC/PNEC ratio > 1 depicted in black ink represents a potential risk for the environment.

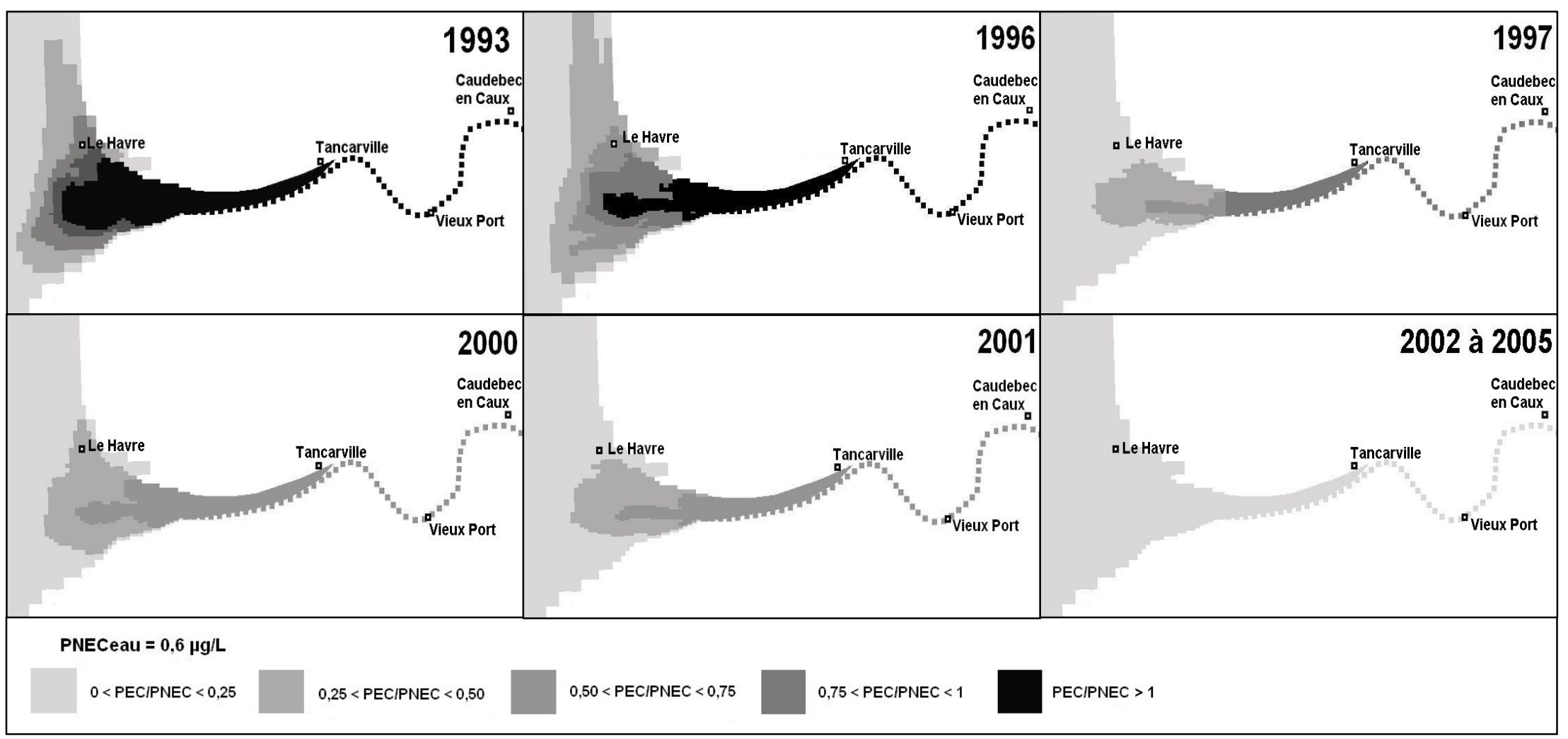


Figure 7. Results of the risk assessment for diuron in 1997, 2000, 2001 and 2005. A PEC/PNEC > 1 ratio depicted in black ink represents a potential risk for the environment.

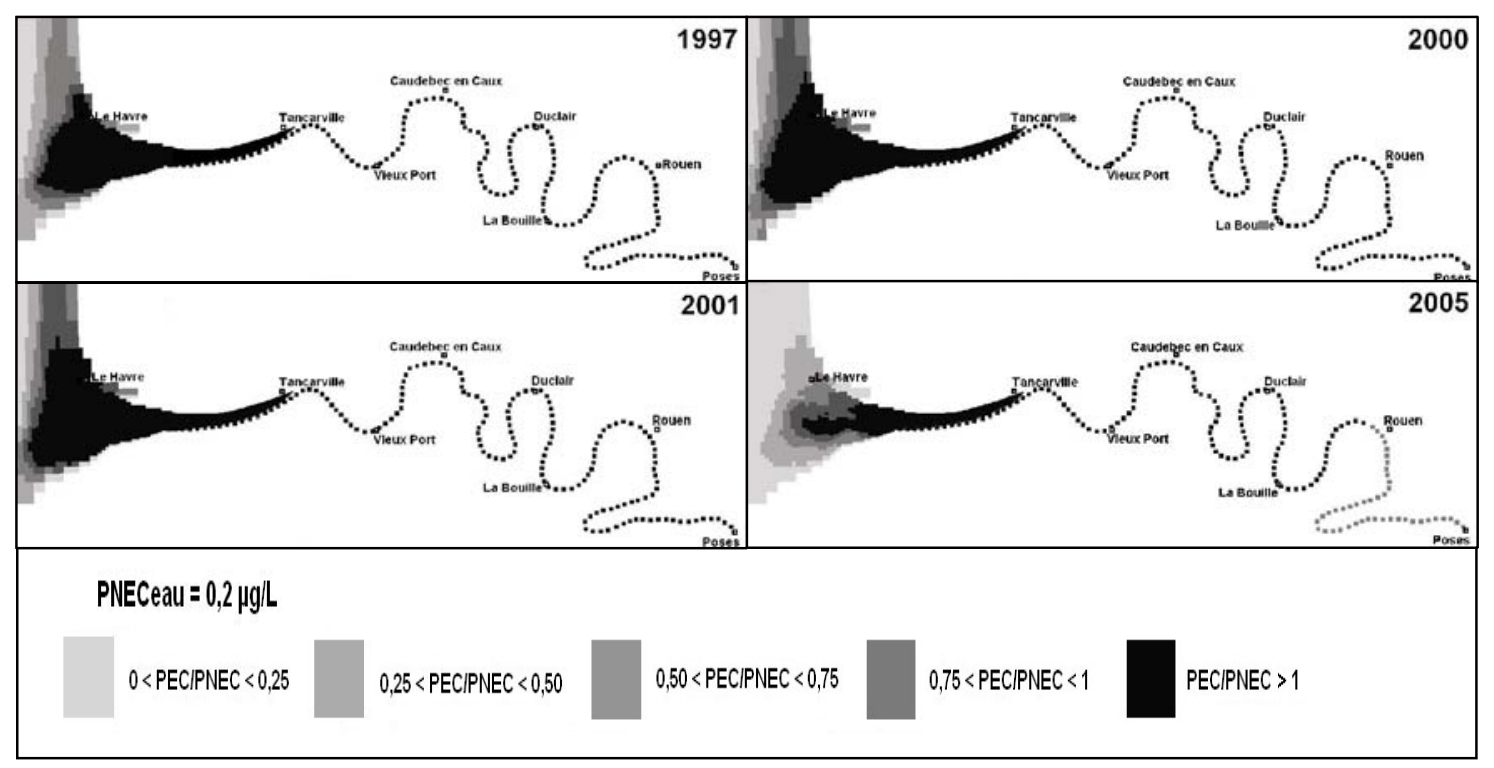


Table 1. Main No Observed Effect Concentrations (NOECs) in $\mu \mathrm{g} \cdot \mathrm{L}^{-1}$ of atrazine and diuron in a single aquatic food chain (FHI, 2005a; FHI, 2005b).

\begin{tabular}{lllll}
\hline Chemicals & Taxa & Species & Effect & NOEC $\left(\mu \mathrm{g} \cdot \mathrm{L}^{-1}\right)$ \\
\hline A trazine & Algae & Scenedesmus subspicatus & Growth & 2 \\
& Crustaceans & Eurytemora affinis & M ortality & 4200 \\
& Vertebrae & Cyprinodon variegates & M ortality & 1900 \\
\hline Diuron & Algae & Scenedesmus subspicatus & Growth & 0.46 \\
& Crustaceans & Daphnia magna & Reproduction & 56 \\
& Vertebrae & Pimephales promelas & Reproduction & 33.4 \\
\hline
\end{tabular}

